\title{
O TRIBUNAL PENAL INTERNACIONAL: COMPOSIÇÃO, COMPETÊNCIA E CONFLITOS APARENTES COM DISPOSIÇÕES CONSTANTES NA CONSTITUIÇÃO BRASILEIRA
}

\section{ARTIGO ORIGINAL}

DELFINO, Leonardo ${ }^{1}$

SILVA, Marco Antonio Marques da ${ }^{2}$

DELFINO, Leonardo. SILVA, Marco Antonio Marques da. O Tribunal Penal Internacional: Composição, competência e conflitos aparentes com disposições constantes na Constituição brasileira. Revista Científica Multidisciplinar Núcleo do Conhecimento. Ano 05, Ed. 08, Vol. 08, pp. 40-53. Agosto de 2020. ISSN: 2448-0959, Link de acesso: https://www.nucleodoconhecimento.com.br/lei/tribunal-penal

\section{RESUMO}

Criado pelo Estatuto de Roma, o Tribunal Penal Internacional (TPI) é órgão ao qual o Estado Brasileiro está submetido à sua jurisdição, malgrado o estudo acerca dos fatos históricos que Ihe deram origem, da sua composição e do seu funcionamento seja relegado por boa parte da doutrina jurídica brasileira. Por meio deste artigo visa-se a debater acerca dos fatos históricos que deram origem à criação do primeiro Tribunal permanente na história com competência para julgamento de pessoas físicas pela prática de crimes contra a humanidade, crimes de guerra, genocídio e agressão, bem como expor as limitações que a jurisdição do Tribunal Penal Internacional encontra na Constituição da República Federativa do Brasil de 1988. A pesquisa foi realizada pelo método bibliográfico e por análise legislativa, concluindo-se que existem conflitos

1 Mestrando em Direito Processual Penal (PUC/SP), Especialista em Direito Processual Civil pelo Complexo de Ensino Superior de Santa Catarina (CESUSC), bacharel em Direito pela Universidade do Sul de Santa Catarina (UNISUL).

${ }^{2}$ Orientador. Doutorado em Direito. Mestrado em Direito. Graduação em Direito. 
aparentes entre o Estatuto de Roma e a Constituição Federal que devem ser sopesados pelo intérprete, a fim de que aquele Diploma não prevaleça sobre a lei maior, assim como que o Tribunal Internacional é um importante instrumento na defesa dos Direitos Humanos.

Palavras-chave: TPI, origem, limitações constitucionais, Constituição Federal de 1988.

\section{OS ANTECEDENTES HISTÓRICOS}

A responsabilização do indivíduo pela prática de condutas extremamente lesivas aos direitos humanos, a ponto de serem compreendidas de crimes no âmbito do Direito Internacional Penal, é evento recente e sua concretização iniciou-se em meados do século XX e atingiu o seu auge no início do século XXI.

Até o término da Segunda Guerra Mundial predominava no plano internacional a ideia de que os governantes não possuíam responsabilidade jurídica pelos genocídios, massacres, mutilações, submissão de grupos étnicos a trabalho escravo e outras atrocidades praticadas contra os direitos humanos, de modo que não havia instrumentos legais e constitucionais para coibir as referidas práticas. O governante, no exercício da soberania estatal, era juridicamente irresponsável por seus atos (LEWANDOWSKI, 2002).

A primeira tentativa de mudança deste panorama ocorreu com os desastrosos resultados da Primeira Guerra Mundial, ocasião em que os países signatários do Tratado de Paz de Versalhes, no artigo 227[3], convencionaram em julgar o imperador Guilherme II por "ofensa suprema contra a moral internacional e santidade dos tratados". Ocorre que o monarca se exilou na Holanda onde permaneceu até a sua morte, sem jamais ser julgado.

Vinte anos após, a escala de atrocidades praticadas por governantes cresceu em grande proporção, de modo que a Segunda Guerra Mundial se notabilizou pela batalha que gerou o maior número de mortes na história da humanidade. 
Por intermédio do Acordo de Londres, firmado pelo Reino Unido, pelos Estados Unidos da América, pela França e pela União das Repúblicas Socialistas Soviéticas em 8 de agosto de 1945, foi criado o Tribunal Internacional Militar (TIM)[4], cuja competência era referente ao julgamento de pessoas que atuaram individualmente ou como membros de organizações que agiram no interesse dos países do "Eixo Europeu" - colaboradores do regime nazista - e cometeram crimes de conspiração, contra a paz, de guerra e contra a humanidade (artigo 6ํㅡ, (a), (b) e (c) do Acordo de Londres (LONDON AGREEMENTE OF 8 AUGUST, 2019) durante a Segunda Guerra Mundial.

O Tribunal Internacional Militar, portanto, foi um tribunal ad hoc instituído pelos países 'vencedores' após o término da guerra e que tinha como escopo o julgamento dos combatentes dos países 'vencidos'.

O modo, a finalidade e por quem foi instituído, por si sós, revelam que pilares edificantes dos principais ordenamentos jurídicos processuais ocidentais foram quebrados com a instituição do TIM, a exemplo do princípio do juízo natural, por se tratar de um tribunal de exceção, isto é, post facto, princípio da imparcialidade dos juízes, que foram escolhidos pelos países que lograram êxito na guerra; princípio da legalidade, porquanto as condutas tachadas por criminosas foram tipificadas após as suas práticas e violação ao contraditório e à ampla defesa, na medida em que as regras procedimentais foram estipuladas de modo favorável à acusação, a quem, exclusivamente, era permitido a apresentação de declarações juramentadas de testemunhas, a inexistência de recursos das decisões e a desconsideração da coisa julgada (non bis in idem) (MAIA, 2017) e a impossibilidade de arguição, por parte da defesa, de impedimento ou suspeição dos magistrados (RAMOS, 2019).

Se por um lado o Tribunal de Nuremberg - que sentenciou doze condenações à morte por enforcamento, três condenações à prisão perpétua, quatro condenações ao cumprimento de penas privativas de liberdade de dez a vinte anos e três absolvições - evidenciou contundentes falhas processuais e procedimentais, de outro pode-se afirmar que foi um importante passo para a maturação da ideia de responsabilização jurídica do indivíduo que atentou contra os direitos humanos, incluindo-se nesta 
categoria os governantes, cuja responsabilidade, até então, era compreendida como inexistente.

No Direito Internacional clássico, a consolidação do Estado como epicentro das relações internacionais após a Paz de Vestfália (1648) teve, como consequência, a restrição da responsabilidade internacional à figura do próprio Estado. Assim, as condutas dos indivíduos (mesmo que fossem agentes públicos) geravam apenas a responsabilidade do Estado (RAMOS, 2019, p. 298).

Entretanto, não obstante o Acordo de Londres ter demonstrado significativa guinada pelos países ocidentais na proteção dos direitos humanos, a segunda metade do Século XX continuou marcada pela prática de crimes contra a humanidade, de guerra e genocídio, pelo que novos Tribunais Penais Internacionais ad hoc foram instituídos - Tribunal para a antiga lugoslávia, sediado em Haia, na Holanda, e Tribunal para Ruanda, sediado em Arusha, na Tanzânia - todos passíveis de críticas em decorrência da sua excepcionalidade.

O Estatuto de Roma do Tribunal Penal Internacional implicou a tão esperada superação ao modelo de tribunais de exceção em sede de Direito Internacional Penal.

\section{O ESTATUTO DE ROMA}

A experiência vivenciada nos julgamentos de crimes contra os direitos humanos por meio de tribunais ad hoc deu margem a severas críticas e demonstrou a necessidade de implementação de um tribunal penal internacional de caráter permanente, anterior aos fatos que a ele seriam levados a julgamento e concebido por meio de regras prédeterminadas.

Diante disso, a Comissão de Direito Internacional da Organização das Nações Unidas (ONU), na década de 1990, promoveu estudos visando à criação de um tribunal internacional permanente, neutro, independente e imparcial, pelo que apresentou à Assembleia Geral um projeto de Estatuto que, discutido por um amplo Comitê entre os anos de 1996 e 1998, deu origem ao Tratado de Roma (RODAS apud MIRANDA, 2009). 
Na Conferência de Roma, realizada em 17 de julho de 1998, foi aprovado o Estatuto do Tribunal Penal Internacional (TPI). A entrada em vigor do Estatuto, conforme previsão do artigo 126, dar-se-ia no primeiro dia do mês seguinte ao termo de um período de sessenta dias após a data do depósito do sexagésimo instrumento de ratificação, o que efetivamente ocorreu em $1^{\circ}$ de julho de 2002 (2019).

O Brasil foi o 69ํㅡㄹ Estado a ratificar o Estatuto de Roma e depositou o seu instrumento de ratificação em 14 de junho de 2002 (ESTATUTO DE ROMA, 2019), de modo que, no plano interno, a Emenda Constitucional n. 45, de 8 de dezembro de 2004, introduziu o $\S 4^{\circ}$ ao artigo $5^{\circ}$ da Constituição Federal, disciplinando que "o Brasil se submete à jurisdição de Tribunal Penal Internacional a cuja criação tenha manifestado adesão".

Por meio do Decreto Legislativo n. 112, de 6 de junho de 2002, o texto foi aprovado pelo Congresso Nacional e, pelo Decreto n. 4.388, de 25 de setembro de 2002, o Brasil ratificou o tratado e passou a incorporar o texto do Estatuto ao ordenamento jurídico nacional, fazendo nascer uma nova jurisdição internacional no âmbito penal brasileiro (SILVA, 2012).

\section{ASPECTOS DESTACADOS NO ESTATUTO DE ROMA}

Da análise do preâmbulo, evidencia-se que os traumas provocados pelas constantes guerras travadas especialmente no século XX, geradoras de significativas lesões aos direitos humanos, consistem no móvel do Estatuto de Roma.

Não à toa que seu exórdio destaca no decurso do Século XX milhões de crianças, homens e mulheres foram vítimas de atrocidades inimagináveis e que estes crimes consistem em uma ameaça à paz, à segurança e ao bem-estar da humanidade; afirmando, ainda, que por afetar toda a comunidade internacional estes delitos não devem ficar impunes, bem como a repressão a eles deve ocorrer em nível nacional, com reforço da cooperação internacional.

O Tribunal Penal Internacional consiste em uma instituição permanente, sediada em Haia, na Holanda, que possui personalidade jurídica internacional e jurisdição sobre 
as pessoas físicas, maiores de dezoito anos de idade, responsáveis pelos crimes de maior gravidade com alcance internacional.

Lewandowski (2002) destaca os seguintes princípios fundamentais que se assentam sobre a atuação do Tribunal Penal Internacional: o princípio da complementaridade, princípio da universalidade, princípio da responsabilidade penal individual, princípio da irrelevância da função oficial, princípio da responsabilidade de comandantes e outros superiores e princípio da imprescritibilidade.

Por meio do princípio da complementaridade, o TPI não pretende, em absoluto, esvaziar a competência que foi confiada pelas Constituições aos tribunais nacionais. O Tribunal apenas será competente nas hipóteses em que ocorra a falência das instituições nacionais nas persecução e punição de um crime internacional (REZEK apud MIRANDA; SILVA, 2009), ou que haja intenção evidente do Estado em utilizar o processo nacional para subtrair do Tribunal Penal Internacional o exercício da jurisdição para privilegiar a impunidade, bem como quando ocorra delonga injustificada no curso do processo ou condução tendenciosa e parcial, incompatível com o alcance da justiça (RAMOS, 2009).

Segundo o princípio da universalidade, os Estados-partes colocam-se integralmente sobre a jurisdição da Corte e dela não podem se subtrair.

O princípio da responsabilidade individual prescreve o Tribunal é competente para o julgamento de pessoas físicas - ao contrário da grande parte das Cortes internacionais que julgam Estados, a exemplo da Corte Interamericana de Direitos Humanos - e que a pessoa responderá individualmente pelos os seus atos, sem prejuízo da responsabilidade do Estado envolvido na prática do crime cujo julgamento seja da competência do TPI.

Previsto no artigo 27 do Estatuto de Roma, o princípio da irrelevância da função de oficial permite que Chefes de Estado, de governo e demais autoridades estatais sejam responsabilizados pela prática de crimes, de modo que as imunidades ou normas de 
procedimento especial, decorrentes da qualidade destas pessoas, não implicarão óbice ao exercício da jurisdição do TPI.

O princípio da responsabilidade de comandantes e outros superiores exige que os chefes militares, ainda que ausentes fisicamente do local dos crimes, envidem todos os esforços possíveis no sentido de evitá-los, sob pena de penalização.

E o princípio da imprescritibilidade corresponde à regra prevista no artigo 29 do Estatuto de Roma, segundo o qual os crimes internacionais cujo julgamento seja de competência do Tribunal Penal Internacional são imprescritíveis.

A competência do TPI restringe-se aos crimes mais graves, que afetam a comunidade internacional no seu conjunto, de modo que foram eleitos como tal no Estatuto de Roma os crimes de genocídio, os crimes contra a humanidade, os crimes de guerra e o crime de agressão.

O crime de genocídio, previsto no artigo 6ํㅡㄹ do Estatuto de Roma, abrange os atos praticados com a intenção de destruir, no todo ou em parte, um grupo nacional, étnico, racial ou religioso, mediante o cometimento de homicídio contra seus membros, ofensas graves à integridade física ou mental, sujeição intencional do grupo a condições de vida com vista a provocar destruição física total ou parcial, imposição de medidas destinadas a impedir nascimentos no seio do grupo e, ainda, transferência à força de crianças para grupos diversos. O referido delito já encontra previsão na legislação nacional (Lei n. 2.889, de $1^{\circ}$ de outubro de 1956), cuja competência para julgamento, caso seja cometido no Brasil ou nas hipóteses previstas no art. $7^{\circ}$ do Código Penal, é, em primeiro momento, da Justiça Federal.

Crimes contra a humanidade, conforme artigo $7^{\circ}$ do ER, referem-se a um quadro de ataque, generalizado ou sistemático, contra qualquer população civil, que implique homicídio, extermínio, escravidão, deportação ou transferência forçada de uma população, prisão ou outra forma de privação da liberdade física grave, em violação das normas fundamentais de direito internacional, tortura, abuso sexual, perseguição de um grupo ou coletividade que possa ser identificado, por motivos políticos, raciais, 
nacionais, étnicos, culturais, religiosos ou de gênero, bem como o desaparecimento forçado de pessoas, apartheid, e outros atos de caráter semelhante e que causem intencionalmente grande sofrimento ou afetem a integridade física ou a saúde física ou mental. Como visto, o referido delito possui tipicidade extremamente aberta, exigindo prudência do intérprete para a sua caracterização, sob pena de violação ao princípio da legalidade, que também é aplicável no âmbito do Direito Internacional Penal (ARAGÃO apud RAMOS, 2019).

Os crimes de guerra - art. 8 do ER - são aqueles cometidos como parte integrante de um plano ou de uma política ou como parte de uma prática em larga escala, que impliquem violações graves às Convenções de Genebra, de 12 de Agosto de 1949, dirigidos contra pessoas ou bens protegidos na referida convenção. Os aludidos delitos podem consistir na prática de homicídio doloso, tortura ou outros tratamentos desumanos, incluindo as experiências biológicas, ato de causar intencionalmente grande sofrimento ou ofensas graves à integridade física ou à saúde, destruição ou apropriação de bens em larga escala - quando não justificada por quaisquer necessidades militares e executadas de forma ilegal e arbitrária. Ainda, 0 ato de compelir prisioneiro de guerra ou pessoa sob proteção a servir nas forças armadas de uma potência inimiga, a privação de um prisioneiro de guerra sem dar-Ihe um julgamento justo e imparcial, a deportação ou transferências ilegais e a tomada de reféns são caracterizados como crime de guerras. Agressões gratuitas à população civil em geral, que não participem diretamente do conflito, também configura crime de guerra, pelo que se pode afirmar que, inclusive em batalha, as regras e os costumes internacionais devem ser cumpridos, de modo que os ataques devem ser dirigidos aos inimigos de forma proporcional para neutralizá-lo, devendo-se, para isso, eleger e executar os meios beligerantes menos lesivos.

A definição do crime de agressão não foi prevista na redação original do Estatuto de Roma, malgrado o nomen juris do delito tenha constado na definição dos crimes de competência do Tribunal. As condutas referentes ao crime em tela somente foram tipificadas com a edição da Resolução RC/Res.6, de 11 de Junho de 2010 (2019), que tachou de crime de agressão o planejamento, a preparação, a iniciação ou execução, 
por uma pessoa em posição efetiva para exercer controle sobre a ação política ou militar de um Estado, de um lado de agressão que, por seu caráter, gravidade e escala, constitua uma violação manifesta à Carta das Nações Unidas. São atos de agressão a invasão ou ataque pelas Forças Armadas de um Estado ao território de outro Estado ou ocupação militar, ainda que temporária, resultante de invasão ou ataque, bem como a anexação, pelo uso da força, de território pertencente a outro Estado, bombardeios pelas Forças Armadas de um Estado contra o território de outro; bloqueio litorâneo, ataques às Forças Armadas, marítimas ou aéreas de outro Estado, empréstimo de território para um terceiro Estado atacar um inimigo e o envio de bandos armados, grupos mercenários para praticar ataques às Forças Armadas de outro Estado.

O Estatuto de Roma estabelece a competência ratione temporis, ao destacar que o Tribunal Penal Internacional somente terá competência no que tange aos crimes cometidos após a sua entrada em vigor, isto é, praticados posteriormente a $1^{\circ}$ de julho de 2002. A referida previsão é de suma importância, na medida em que uma das principais críticas que deram ensejo à criação do TPI era a rejeição, pela comunidade internacional, a tribunais post facto.

A competência territorial cinge-se à prática de crime no território de um Estado-parte, ao cometimento do delito por um nacional de Estado-parte ou à aceitação da competência do Tribunal por um Estado que não seja parte, mediante declaração depositada junto à Secretaria do TPI, consentindo que o Tribunal exerça a sua competência em relação ao crime em questão.

Ramos (2019, p. 317) destaca uma exceção no que tange ao âmbito espacial da competência do TPI:

pode o Conselho de Segurança [da ONU] adotar resolução vinculante adjudicando o caso ao Tribunal Penal Internacional. Foi o Caso de Darfur [...] o primeiro no qual o Conselho de Segurança determinou o início das investigações, mesmo sem a ratificação, pelo Sudão, do Estatuto do TPI.

Em relação à sua composição, o Tribunal Penal Internacional é composto pelos seguintes órgãos: a) a Presidência, b) uma Seção de Recursos, uma Seção de 
julgamento em primeira instância e uma seção de instrução, c) o gabinete do Procurador, d) a Secretaria.

A Presidência é constituída pelo Presidente, pelo Primeiro Vice-Presidente e pelo Segundo Vice-Presidente que ficarão encarregados da administração do Tribunal, exceto do gabinete do Procurador.

Os Juízos que correspondem à Seção de Recursos, integrada pelo Presidente e por quatro juízes, à Seção de julgamento em primeira instância, composta por pelo menos seis juízes e à Seção de Instrução, que conta com mais seis juízes.

Dezoito é o número de juízes que integram o TPI que são eleitos, dentre pessoas de elevada idoneidade moral, imparcialidade e integridade, que reúnam os requisitos para o exercício das mais altas funções judiciais nos seus respectivos países, de modo que o período do mandato é de nove anos, sem possibilidade de reeleição. Os candidatos deverão possuir reconhecida competência em direito penal, direito processual penal, e em matérias relevantes de direito internacional, e a necessária experiência em processos penais na qualidade de juiz, procurador ou outra função semelhante.

O Gabinete do Procurador é um órgão autônomo do Tribunal e possui atuação independente, consistente na coleta de informações, devidamente fundamentadas, sobre crimes da competência do Tribunal, a fim de os examinar e investigar e exercer a ação penal junto ao TPI. O gabinete é presidido pelo Procurador - eleito em escrutínio secreto e por maioria absoluta de votos dos membros da Assembleia dos Estados Partes - auxiliado por Procuradores-Adjuntos, eleitos de forma semelhante para o exercício de mandato de nove anos, vedada a reeleição.

A Secretaria é responsável pelas matérias não judiciais da administração e do funcionamento do Tribunal.

Os idiomas oficiais do Tribunal Penal Internacional são árabe, mandarim, espanhol, francês, inglês e russo, de modo que os idiomas de trabalho são as línguas francesa e inglesa. 
Aos crimes internacionais, cujo julgamento compete ao TPI, são aplicáveis as seguintes sanções: a) a pena de privativa de liberdade pelo período de até trinta anos, b) pena de prisão perpétua, se elevado o grau de ilicitude do fato e as condições pessoais do condenado o justificarem, c) pena de multa e perda dos produtos, bens, valores provenientes, direta ou indiretamente, do crime.

As penas privativas de liberdade poderão ser revistas se a pessoa condenada já tiver cumprido dois terços da reprimenda, ou vinte e cinco anos de prisão em caso de pena de prisão perpétua. Contra os julgamentos, assiste ao Procurador, bem como ao acusado, o direito de recorrer, alegando vício processual, erro de fato, erro de direito, de modo que apenas o acusado, ou o Procurador, quando recorrer em benefício daquele, poderá alegar, também, qualquer outro motivo suscetível de afetar a equidade ou a regularidade do processo ou da sentença.

O artigo 89 do Estatuto de Roma, preconizado visando a expurgar a prática de julgamentos à revelia - empregada em tribunais ad hoc - e com o escopo de dar efetividade aos julgamentos da Corte internacional, dispõe sobre a entrega de pessoas ao Tribunal, salientando que o TPI poderá dirigir um pedido de detenção e entrega de uma pessoa a qualquer Estado em cujo território essa pessoa possa se encontrar, bem como solicitar a cooperação de Estados na detenção e entrega de pessoas.

\section{CONFLITOS APARENTES ENTRE O ESTATUTO DE ROMA DO TRIBUNAL PENAL INTERNACIONAL E A CONSTITUIÇÃO DA REPÚBLICA FEDERATIVA DO BRASIL DE 1988}

Com a aprovação do texto do Estatuto de Roma pelo Decreto n. 4.388 , de 25 de setembro de 2002, o Brasil incorporou o referido Diploma ao ordenamento jurídico nacional, derivando uma nova jurisdição no âmbito do processo penal brasileiro.

Em decorrência disso, as seguintes antinomias entre o Estatuto de Roma e a Constituição Federal foram evidenciadas: 


\subsection{A ENTREGA DE BRASILEIROS AO TRIBUNAL PENAL INTERNACIONAL (ARTIGO 89, § 1, DO ESTATUTO DE ROMA E ART. 5, LI, DA CONSTITUIÇÃO FEDERAL)}

A entrega de brasileiros à jurisdição do Tribunal Penal Internacional é tema que, desde a incorporação do Estatuto de Roma à ordem jurídica pátria, despertou controvérsia.

O inciso LI do artigo 5 da Constituição Federal estabelece que nenhum brasileiro será extraditado, o que, em tese, inviabilizaria a entrega ao TPI.

Sucede que a doutrina visualiza divergência entre os institutos da entrega e da extradição, salientando que "[...] a extradição se caracteriza pela entrega de uma pessoa a um Estado soberano, enquanto a entrega [prevista no art. 89 do ER] se dá a um organismo internacional." (SILVA; FREITAS, 2012, p. 18).

Logo, a entrega de nacional a julgamento por parte do Tribunal Penal Internacional não encontra óbice na Constituição Federal, na medida em que a aludida Corte, após a incorporação do Estatuto de Roma pelo nosso ordenamento, é órgão que integra a jurisdição processual penal brasileira.

\subsection{A PENA DE PRISÃo PERPÉtUA (ART. 77, § 10, “B”, DO ESTATUTO DE ROMA E ART. 5, XLVIII, DA CONSTITUIÇÃO FEDERAL)}

Outro tema controvertido é a previsão, no Estatuto de Roma, de pena privativa de liberdade de caráter perpétuo, o que confronta o disposto no artigo 5ํㅡ, XLVII, da Constituição.

A doutrina dos direitos humanos alega que a vedação constitucional não retira a compatibilidade do Estatuto de Roma com a Constituição, pelo que, em caso de entrega de pessoa ao TPI, não deve ocorrer a comutação de pena, permitindo-se a condenação à pena de caráter perpétuo. 
Nesse sentido, Ramos (2019, p. 337) leciona:

Quanto às penas, a Lei n. 6.815/80 impõe, como condição para o deferimento do pedido de extradição, que o Estado requerente assuma o compromisso de comutar a pena de morte ou corporal em pena privativa de liberdade. Além disso, a jurisprudência do STF, após a extradição n. 855 (Caso Norambuena), exige que seja comutada inclusive a pena de prisão perpétua em pena privativa de liberdade não superior a trinta anos. No caso da entrega, essa exigência não poderia ser imposta por dois motivos: em primeiro lugar, porque há hipótese de revisão da pena, após vinte e cinco anos de cumprimento. Em segundo lugar, fica claro que a vedação da extradição foi construção do STF para impedir que a cooperação entre Estados pudesse se realizar fora de determinados padrões de respeito a direitos humanos (no caso, pena excessiva). Mas o TPI é justamente um tribunal que visa proteger direitos humanos pela punição daqueles que violaram valores essenciais da comunidade internacional.

Mazzuoli (2019, p. 1442) endossa o referido entendimento ao lecionar que

[...] a proibição constitucional de imposição de penas de caráter perpétuo [é] imposição meramente interna [...] relativa aos crimes aqui cometidos e que aqui devam ser julgados, não para crimes da alçada da Corte Penal Internacional.

A despeito dos referidos entendimentos, com ele não podemos concordar.

A vedação à imposição de pena de caráter perpétuo no Brasil constitui direito individual, cláusula pétrea em nosso ordenamento jurídico. Ainda que a República Federativa do Brasil tenha aderido ao Estatuto de Roma, essa adesão só ocorre porque a Constituição Federal assim viabiliza e disciplina. Se esta mesma Carta Magna - de cariz nitidamente humanista e que disciplina a adesão da República Federativa do Brasil a tratados internacionais que versem acerca de direitos humanos - possui disposição intangível vedando aplicação de pena de caráter perpétuo, é de rigor a comutação da pena em caso de entrega de brasileiro, pela RFB, ao Tribunal Penal Internacional, sob pena de os acordos internacionais aos quais o Brasil aderiu tenham poderes derrogadores de cláusulas pétreas, que visam à proteção dos direitos humanos. 
Nesse sentido, ainda que o TPI seja um tribunal que tenha como preceito a proteção dos direitos humanos, tal fato não é juridicamente viável a ponto de permitir a aplicação de uma pena de prisão perpétua a brasileiro a ele entregue pela República Federativa do Brasil. Se se tem em mira que os direitos humanos devem ser sempre privilegiados, a primazia, no conflito em tela, ocorre com a comutação da pena em decorrência da previsão constitucional - limitando a sanha persecutória, e não com a imposição de pena de caráter perpétuo. Ademais, a possibilidade de revisão da pena não retira o seu caráter perpétuo, pelo que os órgãos pertencentes à jurisdição processual penal brasileira, incluindo-se o TPI em caso de julgamento de brasileiro entregue pela República Federativa do Brasil, devem sofrer a limitação punitiva prevista no artigo 5ำ, XLVIII, da Constituição Federal.

\section{CONCLUSÃO}

O Estatuto de Roma do Tribunal Penal Internacional representou importante avanço para o Direito Internacional de modo a dar efetividade à proteção à dignidade da pessoa humana e conseguintemente aos direitos humanos.

A instituição de tribunais ad hoc para julgamento de crimes contra os direitos humanos praticados em contextos de guerra demonstrou, em vez da realização de justiça, o cometimento de novas barbáries pelos vencedores das guerras contra os vencidos, a exemplo de imposição de penas de morte em procedimentos que desprezaram o devido processo legal àqueles levados a julgamento.

O Tribunal Penal Internacional rompeu com este paradigma.

Malgrado os crimes internacionais previstos no Estatuto de Roma sejam, em grande maioria, de tipo aberto, o que pode violar em caso de excesso hermenêutico o princípio da legalidade, as regras relativas à sua instituição, jurisdição e competência são bastantes claras a ponto de transformá-lo em uma corte permanente que propicia à pessoa acusada um julgamento isento. 
O Estatuto de Roma, talvez um primeiro passo rumo à codificação de regras de direito internacional penal e processual penal, trouxe-nos a ideia de que os direitos humanos não são passíveis de violação pelos governantes nem mesmo em hipótese de guerra declarada.

Espera-se que os Estados, partes ou não no Tratado de Roma, estejam vigilantes na proteção e na não violação dos direitos humanos e que possam, assim como o Conselho de Segurança das Nações Unidas, submeter à apreciação do Tribunal Penal Internacional casos em que ocorreu a prática de crimes internacionais para julgamento, de forma parcial - evitando-se assim a seletividade de países com menor influência na ordem internacional, sob pena de enfraquecer o Tribunal e a isenção de seus julgamentos, a fim de tornar efetiva a proteção dos direitos humanos, de modo a evitar a ocorrência de atrocidades a exemplo daquelas vivenciadas no Século XX.

\section{REFERÊNCIAS}

BRASIL. Resolução RC/Res.6, de 11 de Junho de 2010. Disponível em: https://treaties.un.org/doc/source/docs/RC-Res.6-ENG.pdf. Acesso em: 23 nov. 2019.

COUR PÉNALE INTERNATIONALE. Disponível em: https://www.icc-cpi.int/about. Acesso em: 23 nov. 2019.

ESTATUTO DE ROMA. Disponível em: http://www.mpm.mp.br/estatuto-de-roma-dotpi-completa-20-anos/. Acesso em: 23 nov. 2019.

GOOGLE. Disponível em: https://treaties.un.org/doc/source/docs/RC-Res.6-ENG.pdf. Acesso em: 23 nov. 2019

LEWANDOWSKI, Enrique Ricardo. O Tribunal Penal Internacional: de uma cultura da impunidade para uma cultura de responsabilidade. Estudos avançados, São Paulo, v. 16 , n. 45 , p. 188 , maio/ago. 2002.

LONDON AGREEMENTE OF 8 AUGUST 1945. Disponível em: https://www.sahistory.org.za/sites/default/files/file\%20uploads\%20/London\%20Agree 
ment\%20by\%20United\%20Nations\%2C\%208\%20August\%201945.pdf. Acesso em: 23 nov. 2019.

MAIA, Renan de Marco D’Andrea. A estrada para Roma: A evolução do Direito Internacional Penal. Ribeirão Preto: O autor, 2017.

MAZZUOLI, Valério de Oliveira. Curso de direito internacional público. 12. ed. Rio de Janeiro: Forense, 2019.

RAMOS, André de Carvalho. Processo internacional de direitos humanos. 6. ed. São Paulo: Saraiva Educação, 2019.

REZEK, Francisco. Tribunal Internacional - Princípio da complementaridade e soberania. In: MIRANDA, Jorge; SILVA, Marco Antonio Marques da (coordenação). Tratado Luso-Brasileiro da dignidade humana. São Paulo: Quartier Latin, 2009.

RODAS, João Grandino. Tribunal Penal Internacional. A entrega de nacionais. In: MIRANDA, Jorge; SILVA, Marco Antonio Marques da (coordenação). Tratado LusoBrasileiro da dignidade humana. São Paulo: Quartier Latin, 2009.

SILVA, Marco Antonio Marques da; FREITAS, Jayme Walmer de. Código de processo penal comentado. São Paulo: Saraiva, 2012.

TREATY OF VERSAILLES. Disponível em: https://www.loc.gov/law/help/ustreaties/bevans/m-ust000002-0043.pdf. Acesso em: 23 nov. 2019.

\section{APÊNDICE - REFERÊNCIAS DE NOTA DE RODAPÉ}

3. Article 227 - The Allied and Associated Powers publicy arraign William II of Hohenzollern, formerly German Emperor, for a supreme offence against international morality and the sanctity of treaties.

A special tribunal will be constituted to try the accused, thereby assuring him the guarantees essential to the right of defence. It will be composed of five judges, one 
appointed by each of the following Powers: namely, the United States of America, Great Britain, France, Italy and Japan.

In its decision the tribunal will be guided by the highest motives of international policy, with a view to vindicating the solemn obligations of international undertakings and the validity of international morality. It will be its duty to fix the punishment which it considers should be imposed.

The Allied and Associated Powers will address a request to the Government of the Netherlands for the surrender to them of the ex-Emperor in order that he may be put on trial. Disponível em https://www.loc.gov/law/help/us-treaties/bevans/m-ust0000020043.pdf. Acesso em: 23 nov. 2019.

4. Também conhecido por Tribunal de Nuremberg, uma vez que as sessões de julgamento foram realizadas na referida cidade alemã, conforme art. 22 do Acordo de Londres.

Enviado: Agosto, 2020.

Aprovado: Agosto, 2020. 